\title{
Evaluation of clinical value and potential mechanism of MTFR2 in lung adenocarcinoma via bioinformatics
}

\author{
Cheng Chen, Yang Tang, Wen-Dong Qu, Xu Han, Jie-Bin Zuo, Qing-Yong Cai, Gang Xu, Yong-Xiang Song ${ }^{*}$ and \\ Xi-Xian Ke*
}

\begin{abstract}
Background: Mitochondrial fission regulator 2 (MTFR2) was involved in the progression and development of various cancers. However, the relationship between MTFR2 with lung adenocarcinoma (LUAD) had not been reported. Herein, this study analyzed the clinical significance and potential mechanisms of MTFR2 in LUAD via bioinformatics tools.
\end{abstract}

Results: We found that the level of MTFR2 was increased, and correlated with sex, age, smoking history, neoplasm staging, histological subtype and TP53 mutation status in LUAD patients. Kaplan-Meier survival analysis showed LUAD patients with increased MTFR2 had a poor prognosis. In addition, univariate COX regression analysis showed neoplasm staging, T stage, distant metastasis and MTFR2 level were risk factors for the prognosis of LUAD. A total of 1127 genes were coexpressed with MTFR2, including 840 positive and 208 negative related genes. KEGG and GSEA found that MTFR2 participated in the progression of LUAD by affecting cell cycle, DNA replication, homologous recombination, p53 signaling pathway and other mechanisms. The top 10 coexpressed genes, namely CDK1, CDC20, CCNB1, PLK1, CCNA2, AURKB, CCNB2, BUB1B, MAD2L1 and BUB1 were highly expressed, and were associated with poor prognosis in LUAD.

Conclusions: Consequently, we elucidated MTFR2 was a biomarker for diagnosis and poor prognosis in LUAD, and might participate in the progression of LUAD via affecting cell cycle, DNA replication, homologous recombination and p53 signaling pathway.

Keywords: Lung adenocarcinoma, Prognosis, MTFR2, Bioinformatics, Biomarker

\section{Introduction}

Non-small cell lung cancer (NSCLC) was one of the most common malignant tumors in the world, and lung adenocarcinoma (LUAD) was one of the common subtype of NSCLC $[1,2]$. LUAD patients in early stage got improved long-term prognosis by surgery and neoadjuvant chemotherapy, while due to incomplete excision, primary and secondary drug resistance and other

\footnotetext{
*Correspondence: songtang2004@163.com; kexixian@zmu.edu.cn Department of Thoracic Surgery, Affiliated Hospital of Zunyi Medical University, Zunyi 563000, Guizhou, China
}

reasons, recurrence and metastasis happened. The 5year survival rate of the patients was still very low, and its treatment was extremely challenging $[2,3]$. In recent years, targeted therapy had greatly improved the prognosis of patients with LUAD, but the mortality of patients with LUAD remained at a high level [4-6]. Therefore, it was of great significance to further discover the novel molecules and explore their regulatory mechanisms involved in the occurrence and development of LUAD resulting in finding novel therapeutic targets.

(c) The Author(s). 2021 Open Access This article is licensed under a Creative Commons Attribution 4.0 International License, which permits use, sharing, adaptation, distribution and reproduction in any medium or format, as long as you give appropriate credit to the original author(s) and the source, provide a link to the Creative Commons licence, and indicate if changes were made. The images or other third party material in this article are included in the article's Creative Commons licence, unless indicated otherwise in a credit line to the material. If material is not included in the article's Creative Commons licence and your intended use is not permitted by statutory regulation or exceeds the permitted use, you will need to obtain permission directly from the copyright holder. To view a copy of this licence, visit http://creativecommons.org/licenses/by/4.0/ The Creative Commons Public Domain Dedication waiver (http://creativecommons.org/publicdomain/zero/1.0/) applies to the data made available in this article, unless otherwise stated in a credit line to the data. 
Mitochondrial fission regulator 2 (MTFR2), also known as FAM54A, was located on the 6q23.2 chromosome and belonged to the MTFR family. Abnormal mitosis of mitochondria was related to the pathogenesis of many diseases, as well as occurrence and prognosis of several tumors [7-11]. MTFR2 was up-regulated in breast cancer and was related to age, lymph node metastasis, and prognosis in HER2 positive breast cancer patients. Knockout of MTFR2 prohibited the proliferation, migration and invasion of breast cancer cells, and blocked epithelial-stromal transformation (EMT) [8]. MTFR2 affected the transcription of TTK by activating the transcriptional promoter. MTFR2-dependent TTK regulation played a key role in maintaining GSC (Glioma stem-like cells) in glioma, and may be a target molecule of new drugs for glioma patients [12]. Whereas, at present, rare researches were focused on MTFR2 in other tumors including LUAD, except for those cancers listed above. Herein, the present study explored the clinical value and potential regulatory mechanism of MTFR2 in the progression of LUAD through multiple databases.

\section{Results}

MTFR2 was upregulated and correlated with sex, age, smoking history, cancer stage, histological subtype and TP53 mutation status in LUAD patients

MTFR2 was abnormally expressed in pan-cancerous tissues, and was mainly over-expressed in a variety of tumor tissues (Fig. 1). In detail, in the Oncomine database, MTFR2 was highly expressed in breast cancer, colorectal cancer, gastric cancer, lung cancer and other tumor tissues, while lowly- expressed in brain nerve tumor, breast cancer, leukemia and other tumor tissues (Fig. 1A). In the Timer database, MTFR2 was highly expressed in BLCA, BRCA, CHOL, LUSC, LUAD and other tumor tissues (Fig. 1B).

In addition, we found consistent results in the Ualcan database, where MTFR2 was highly expressed in LUAD tissues (Table 1). In addition, in the TCGA database, the expression of MTFR2 was increased in unpaired LUAD patients (Fig. 2A) and in 57 pairs of LUAD patients (Fig. 2B).

In the Ualcan database, we found that the expression of MTFR2 was related to the clinicopathological features of LUAD patients (Table 1). In detail, the level of MTFR2 was related to the sex (Male vs Female), Age (Age(41-60Yrs) vs Age (61-80Yrs)), Smoking (Non smoker vs Smoker; Non smoker vs Reformed smoker2; Smoker vs Reformed smoker1; Smoker vs Reformed smoker2; Reformed smoker1 vs Reformed smoker2), histological subtype (NOS vs Mixed; NOS vs LBC-Non Mucinous; NOS vs Solid Pattern Predominant; NOS vs Acinar; NOS vs LBC-Mucinous; NOS vs Papillary; Mixed vs Solid Pattern Predominant; Mixed vs LBCMucinous; Mixed vs Papillary; Clear Cell vs LBC-Non Mucinous; Clear Cell vs Papillary; LBC-Non Mucinous vs Solid Pattern Predominant; LBC-Non Mucinous vs LBC-Mucinous; Solid Pattern Predominant vs LBCMucinous; Solid Pattern Predominant vs Mucinous carcinoma; Solid Pattern Predominant vs Papillary; Acinar vs LBC-Mucinous; LBC-Mucinous vs Papillary) and TP53 mutation (TP53-Mutant vs TP53-Non Mutant) of LUAD patients.

In TCGA database, the area under the curve (AUC) showed that the level of MTFR2 had a diagnostic value in LUAD patients via the ROC analysis (Fig. $2 \mathrm{C}$ and $\mathrm{D}$ ). Further Kaplan-Meier analysis showed that the LUAD patients with increased MTFR2 had a poor prognosis (Fig. 2E). In addition, in the Kaplan-Meier Plotter

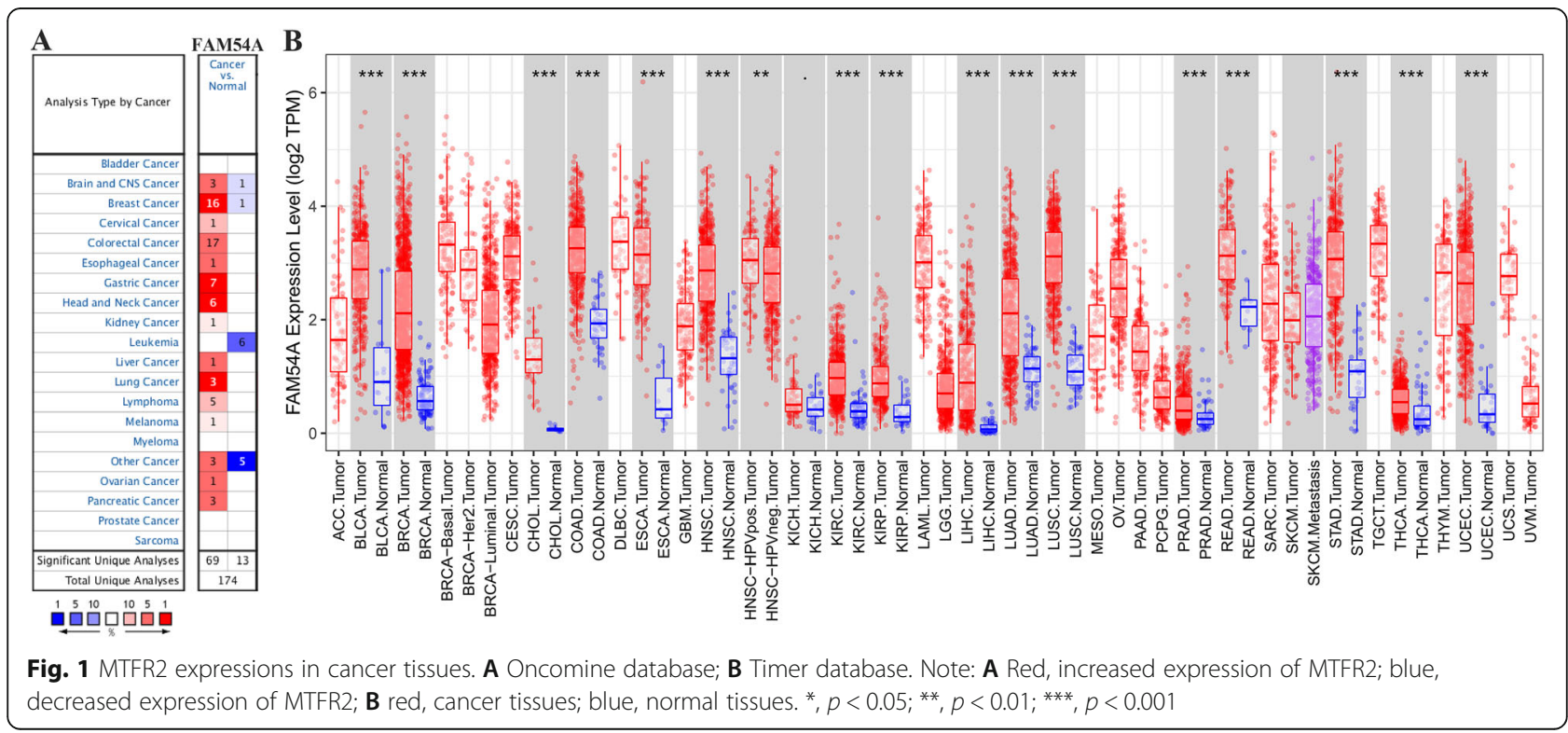


Table 1 The expression of MTFR2 in Ualcan database was correlated to the clinicopathological characteristics in LUAD patients

\begin{tabular}{|c|c|}
\hline Clinicopathological characteristics & $p$ value \\
\hline \multicolumn{2}{|l|}{ Expression } \\
\hline Normal-vs-Primary & 1.62447832963153E-12 \\
\hline \multicolumn{2}{|l|}{ Gender } \\
\hline Male-vs-Female & 4.185800E-02 \\
\hline \multicolumn{2}{|l|}{ Age } \\
\hline Age(41-60Yrs)-vs-Age(61-80Yrs) & 1.089890E-02 \\
\hline \multicolumn{2}{|l|}{ Smoking } \\
\hline Non smoker-vs-Smoker & 7.3849000004067E-07 \\
\hline Non smoker-vs-Reformed smoker2 & $6.560800 \mathrm{E}-03$ \\
\hline Smoker-vs-Reformed smoker1 & $1.53600000496468 \mathrm{E}-08$ \\
\hline Smoker-vs-Reformed smoker2 & 1.978210E-03 \\
\hline Reformed smoker1-vs-Reformed smoker2 & $1.955780 \mathrm{E}-04$ \\
\hline \multicolumn{2}{|l|}{ Cancer stages } \\
\hline Stage1-vs-Stage2 & 4.427500E-02 \\
\hline \multicolumn{2}{|l|}{ Tissue types } \\
\hline NOS-vs-Mixed & 2.900200E-02 \\
\hline NOS-vs-LBC-Non Mucinous & $2.038200 \mathrm{E}-03$ \\
\hline NOS-vs-Solid Pattern Predominant & $2.599600 \mathrm{E}-02$ \\
\hline NOS-vs-Acinar & 5.378900E-03 \\
\hline NOS-vs-LBC-Mucinous & $1.70860000003881 \mathrm{E}-06$ \\
\hline NOS-vs-Papillary & $1.027880 \mathrm{E}-04$ \\
\hline Mixed-vs-Solid Pattern Predominant & 1.196000E-02 \\
\hline Mixed-vs-LBC-Mucinous & 4.00150000001709E-06 \\
\hline Mixed-vs-Papillary & $4.149500 \mathrm{E}-02$ \\
\hline Clear Cell-vs-LBC-Non Mucinous & 4.028200E-02 \\
\hline Clear Cell-vs-Papillary & $2.063500 \mathrm{E}-02$ \\
\hline LBC-Non Mucinous-vs-Solid Pattern Predominant & 4.452100E-02 \\
\hline LBC-Non Mucinous-vs-LBC-Mucinous & 1.174210E-02 \\
\hline Solid Pattern Predominant-vs-LBC-Mucinous & 1.926450E-02 \\
\hline Solid Pattern Predominant-vs-Mucinous carcinoma & 4.480600E-03 \\
\hline Solid Pattern Predominant-vs-Papillary & 3.801800E-02 \\
\hline Acinar-vs-LBC-Mucinous & 1.693590E-02 \\
\hline LBC-Mucinous-vs-Papillary & 1.804030E-02 \\
\hline
\end{tabular}

Note: Reformed smoker 1, Reformed smoker (< 15 years); Reformed smoker 2, Reformed smoker ( $>15$ years); NOS, Lung Adenocarcinoma-Not Otherwise Specified; Mixed, Lung Adenocarcinoma Mixed subtype; Clear Cell, Lung Clear Cell Adenocarcinoma; LBC-Nonmucinous, Lung Bronchioloalveolar Carcinoma Non mucinous; Solid Pattern Predominant, Lung Solid Pattern Predominant Adenocarcinoma; Acinar, Lung Acinar Adenocarcinoma; LBC-Mucinous, Lung Bronchioloalveolar Carcinoma Mucinous; Mucinous, Mucinous (Colloid) Carcinoma; Papillary, Lung Papillary Adenocarcinoma; Mucinous, Lung Mucinous Adenocarcinoma; Micropapillary, Lung Micropapillary Adenocarcinoma; Signet Ring, Lung Signet Ring Adenocarcinoma

database, the levels of MTFR2 (228069_at) and MTFR2 (234944_at) were associated with the overall survival and early disease progression of LUAD patients (Fig. 2F-I). Univariate Cox analysis of complete clinical data of LUAD patients in TCGA database showed that cancer stage, $\mathrm{T}$ stage, lymphatic metastasis as well as MTFR2 expression were risk factors for the prognosis of LUAD patients (Table 2). Further multivariate Cox analysis showed that cancer stage was an independent risk factor for the prognosis of LUAD patients (Table 2). 

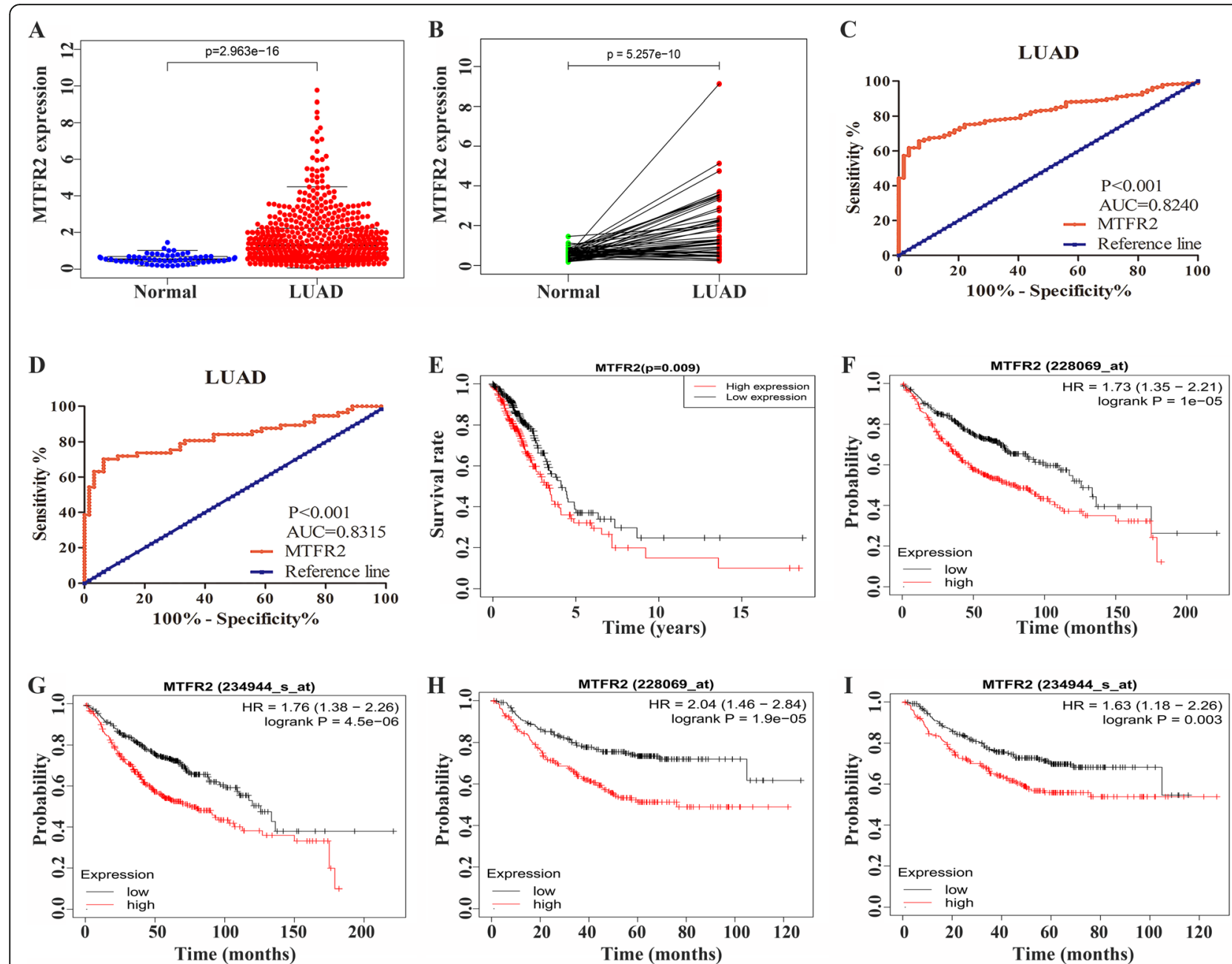

Fig. 2 The expression of MTFR2 was correlated to diagnosis and prognosis in LUAD patients. A Expression of MTFR2 in unpaired LUAD tissues; B Expression of MTFR2 in 57 paired LUAD tissues; C The diagnostic value of MTFR2 in unpaired LUAD tissues; D The diagnostic value of MTFR2 in 57 paired LUAD tissues; $\mathbf{E}$ The expression of MTFR2 in TCGA database was correlated with the OS of LUAD patients; F-G The levels of MTFR2 (228069_at) and MTFR2 (234944_at) were correlated to the OS of LUAD patients with Kaplan-Meier Plotter analysis; H-I The levels of MTFR2 (228069_at) and MTFR2 (234944_at) were correlated to the early progression of LUAD patients with Kaplan-Meier Plotter analysis. Note: Normal, normal lung tissues; LUAD, lung adenocarcinoma tissues; AUC, Area under curve

\section{Screening of MTFR2 co-expressed genes}

We screened 1127 MTFR2 co-expressed genes in TCGA database by screening conditions, most of which were positive related genes. Among them, there were 840 positive and 208 negative related genes (S1 Table). The top 10 genes that were positively and negatively related to MTFR2 (Table 3). The expression of the top 10 positive and negative related genes of MTFR2 in LUAD tissues from TCGA were abnormally expressed (Fig. 3).

\section{Analysis of MTFR2 function and its coexpressed genes by GO, KEGG and GSEA}

In order to further understand the potential function of MTFR2 in the development of LUAD, we carried out GO and KEGG analysis of MTFR2 co-expressed genes. MTFR2 coexpressed genes were involved in $\mathrm{BP}, \mathrm{CC}$ and $\mathrm{MF}$
(Fig. 4A-C), and in details, were mainly involved in DNA replication, chromosome segregation, mitotic nuclear division, mitotic cell cycle phase transition and other processes (S2 Table). KEGG pathway analysis indicated MTFR2 coexpressed genes were mainly involved in cell cycle, DNA replication, proteasome, homologous recombination, spliceosome, nucleotide excision repair, human T-cell leukemia virus 1 infection, p53 signaling pathway and other signal pathways (Fig. 4D and Table 4). What's more, in GSEA database, we found that cell cycle, DNA_replication, homologous recombination, p53 signal pathway, oocyte meiosis and base_excision repair signaling pathways were highly enriched in MTFR2 highly expressed group (Fig. 5 and Table 5). To sum up, these results suggested that MTFR2 might regulate the progress of LUAD through cell cycle, DNA replication, homologous recombination and p53 signaling pathway. 
Table 2 COX regression analysis of the correlation between clinicopathological features with prognosis

\begin{tabular}{lllll}
\hline Clinical characteristics & HR & HR 95\% Cl low & HR 95\% Cl up & p value \\
\hline a & & & & \\
Age & 1.057406203 & 0.713393673 & 1.567308372 & 0.781014797 \\
Gender & 1.00097432 & 0.698837323 & 1.433737948 & 0.995761563 \\
Stage & 1.64465101 & 1.396688 & 1.93663649 & $2.42 \mathrm{E}-09$ \\
T & 1.623091548 & 1.309819761 & 2.011289072 & $0.57 \mathrm{E}-06$ \\
M & 1.681168333 & 0.923680619 & 3.059853055 & 0.08910352 \\
N & 1.792676516 & 1.464854278 & 2.193862653 & $1.47 \mathrm{E}-08$ \\
MTFR2 & 1.096892408 & 1.002541345 & 1.200123029 & 0.043876089 \\
b & & & & \\
Stage & 1.37421707 & 1.094758223 & 1.725013356 & 0.006135636 \\
T & 1.223211397 & 0.971744105 & 1.539753227 & 0.086187124 \\
N & 1.283860776 & 0.991173421 & 1.662976889 & 0.05838382 \\
MTFR2 & 1.062548364 & 0.964968929 & 1.169995211 & 0.217045634 \\
\hline
\end{tabular}

\section{Construction of PPI network and the expressions of hub genes and their prognostic value}

By identifying the function of MTFR2 co-expressed genes, the potential biological function of MTFR2 was also inferred. The top 10 Hub genes in the PPI network were selected by the CytoHubba plug-in as CDK1, CDC20, CCNB1, PLK1, CCNA2, AURKB, CCNB2,

Table 3 The top 10 genes with positive and negative correlation to MTFR2

\begin{tabular}{llll}
\hline Gene & Corgene & Cor & $\boldsymbol{p}$ value \\
\hline MTFR2 & CENPW & 0.876 & $1.08 \mathrm{E}-170$ \\
MTFR2 & TTK & 0.849 & $7.63 \mathrm{E}-150$ \\
MTFR2 & NCAPH & 0.848 & $4.00 \mathrm{E}-149$ \\
MTFR2 & RAD51 & 0.835 & $1.43 \mathrm{E}-140$ \\
MTFR2 & CENPA & 0.827 & $2.59 \mathrm{E}-135$ \\
MTFR2 & KIF2C & 0.817 & $2.83 \mathrm{E}-129$ \\
MTFR2 & BUB1 & 0.817 & $1.98 \mathrm{E}-129$ \\
MTFR2 & CDCA8 & 0.816 & $5.28 \mathrm{E}-129$ \\
MTFR2 & HJURP & 0.814 & $7.81 \mathrm{E}-128$ \\
MTFR2 & CDCA5 & 0.814 & $1.26 \mathrm{E}-127$ \\
MTFR2 & C16orf89 & -0.655 & $7.35 \mathrm{E}-67$ \\
MTFR2 & CRY2 & -0.628 & $3.92 \mathrm{E}-60$ \\
MTFR2 & C1Orf116 & -0.585 & $1.60 \mathrm{E}-50$ \\
MTFR2 & CYP4B1 & -0.583 & $5.72 \mathrm{E}-50$ \\
MTFR2 & SELENBP1 & -0.58 & $2.16 \mathrm{E}-49$ \\
MTFR2 & CACNA2D2 & -0.576 & $1.56 \mathrm{E}-48$ \\
MTFR2 & ADGRF5 & -0.568 & $4.68 \mathrm{E}-47$ \\
MTFR2 & NAPSA & -0.561 & $1.09 \mathrm{E}-45$ \\
MTFR2 & SNED1 & -0.558 & $4.89 \mathrm{E}-45$ \\
MTFR2 & NR3C2 & -0.557 & $6.44 \mathrm{E}-45$ \\
\hline Nof Cor & CO & &
\end{tabular}

Note: Corgene, co-expressed gene; Cor, correlation coefficient
BUB1B, MAD2L1 and BUB1 (S1 Fig and Table 6). The expression of MTFR2 was correlated with that of CDK1, CDC20, CCNB1, PLK1, CCNA2, AURKB, CCNB2, BUB1B, MAD2L1 and BUB1 (Fig. 6). In addition, GEPIA database was used to analyze the expressions of Hub genes and their prognostic values. We found that the expressions of CDK1, CDC20, CCNB1, PLK1, CCNA2, AURKB, CCNB2, BUB1B, MAD2L1 and BUB1 genes were significantly increased in LUAD tissues (Fig. 7). The top10 Hub genes were associated with OS of LUAD patients, and CDK1, CCNB1, PLK1, AURKB, CCNB2, BUB1B and BUB1 were associated with DFS in LUAD patients with disease-free progression (Fig. 8).

\section{Discussion}

Mitochondria, via regulating the membrane potential, participated in programmed cell death as well as cell proliferation [13, 14]. MTFR2 played an vital role in promoting the division of mitochondria in cells. Under pathological condition, abnormal mitosis of mitochondria was related to the development of tumors $[10,11]$. At present, studies found that the expression of MTFR2 in breast cancer tissues were increased, and was correlated to the clinicopathological features and poor prognosis of patients. Interfering with MTFR2 inhibited the growth and migration of breast cancer cells, indicating its biological role as oncogene and with prognostic value [8]. However, the role of MTFR2 in LUAD was still not been elucidated. In present study, it was found for the first time that MTFR2 was highly expressed in LUAD tissues in multiple databases, and the level of MTFR2 was related to sex, age, smoking history, cancer stage, histological subtypes and TP53 mutation status in LUAD patients. ROC analysis showed that the expression of MTFR2 had diagnostic value in LUAD. Kaplan- 

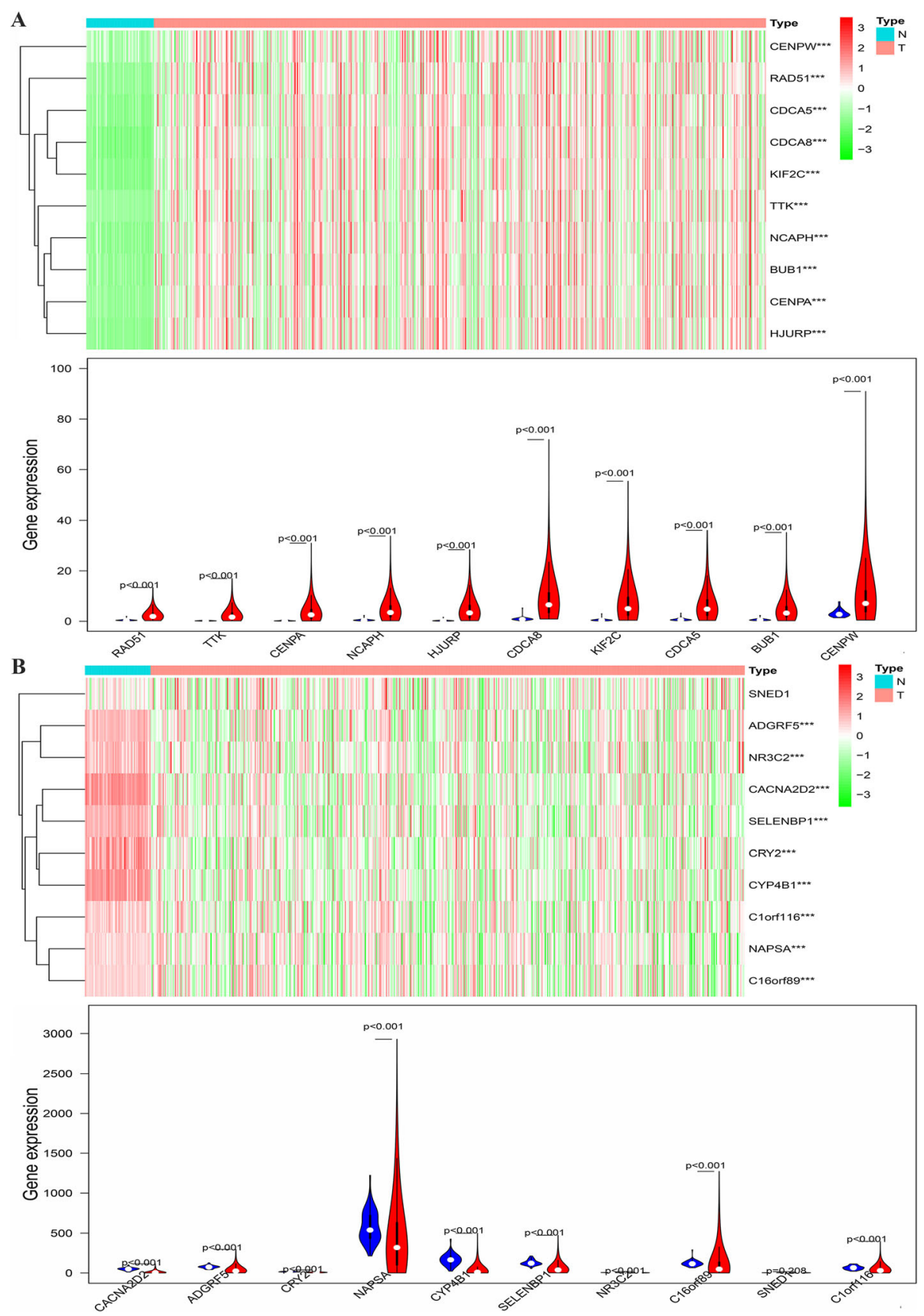

Fig. 3 The expressions of the top 10 positive and negative related genes of MTFR2 in LUAD tissues. A The top 10 positively correlated genes; B The top 10 negatively correlated genes. Note: ***, $p<0.001 ; \mathrm{N}$, normal lung tissue; T, lung adenocarcinoma tissue

Meier analysis showed that the overall survival time of LUAD patients with increased MTFR2 expression was related to the early disease progression. Univariate Cox analysis showed that cancer stage, $\mathrm{T}$ stage, distant metastasis and the level of MTFR2 were risk factors for the prognosis in LUAD. These results indicated that MTFR2 played an important role in the development of LUAD.

Abnormal cell cycle leaded to abnormal regulation of cell growth and induced overgrowth of cells, resulting in poor prognosis of tumor patients. Therefore, through a detailed understanding of the mechanism of tumor growth and inhibition of tumor occurrence and development, the prognosis of patients could be improved [1517]. Nichols et al. reported that high mutation burden in LUAD patients with increased HORMAD1 expression decreased the survival rate of LUAD patients. HORMAD1 was one of the key genes in the process of homologous recombination (HR), and promoted the 


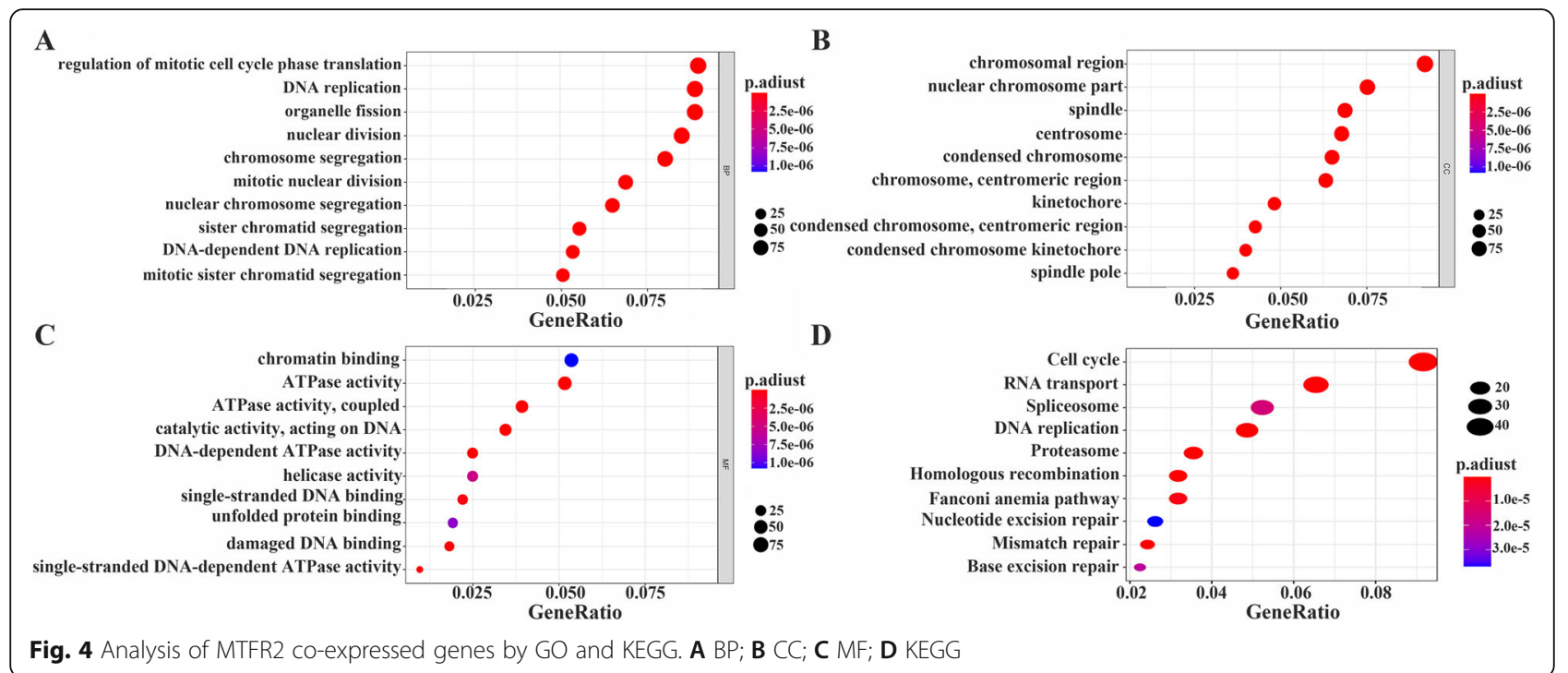

formation of RAD51 filaments to participate in the process of homologous recombination. Interfering with HORMAD1 reduced the growth of tumor cells [18]. FAM111B was highly expressed in LUAD tissues. LUAD patients with high expression of FAD111B had low relapse-free survival (RFS) and overall survival (OS). Interfering with FAM111B inhibited the proliferation, cell cycle arrest and migration of LUAD cells and the ability of tumor formation in nude mice, but induced apoptosis. FAM111B might regulate the growth of LUAD through p53 signaling pathway, inhibited the expression of BAG3 and BCL2, and played an important role in cell cycle and apoptosis [19]. In present study, we found that MTFR2 coexpressed genes were mainly involved in cell cycle, DNA replication, homologous recombination, p53 signaling pathway and other signaling

Table 4 MTFR2 co-expressed genes by KEGG

\begin{tabular}{|c|c|c|c|c|}
\hline ID & Description & Count & $p$ value & $p$ adjust \\
\hline hsa04110 & Cell cycle & 49 & $2.54 \mathrm{E}-26$ & 7.53E-24 \\
\hline hsa03030 & DNA replication & 26 & $1.92 \mathrm{E}-23$ & $2.84 \mathrm{E}-21$ \\
\hline hsa03050 & Proteasome & 19 & $2.45 \mathrm{E}-11$ & 2.42E-09 \\
\hline hsa03440 & Homologous recombination & 17 & $2.60 \mathrm{E}-10$ & 1.59E-08 \\
\hline hsa03430 & Mismatch repair & 13 & $2.69 \mathrm{E}-10$ & 1.59E-08 \\
\hline hsa03013 & RNA transport & 35 & $5.88 \mathrm{E}-09$ & $2.90 \mathrm{E}-07$ \\
\hline hsa03460 & Fanconi anemia pathway & 17 & $3.58 \mathrm{E}-08$ & $1.52 \mathrm{E}-06$ \\
\hline hsa03040 & Spliceosome & 28 & 4.24E-07 & 1.57E-05 \\
\hline hsa03410 & Base excision repair & 12 & $6.52 \mathrm{E}-07$ & $2.14 \mathrm{E}-05$ \\
\hline hsa03420 & Nucleotide excision repair & 14 & $1.25 \mathrm{E}-06$ & 3.69E-05 \\
\hline hsa04114 & Oocyte meiosis & 24 & $2.97 \mathrm{E}-06$ & $8.00 \mathrm{E}-05$ \\
\hline hsa00670 & One carbon pool by folate & 8 & $2.25 \mathrm{E}-05$ & 0.000555487 \\
\hline hsa03008 & Ribosome biogenesis in eukaryotes & 20 & $3.63 \mathrm{E}-05$ & 0.000826201 \\
\hline hsa04218 & Cellular senescence & 24 & 0.000136465 & 0.002885268 \\
\hline hsa04914 & Progesterone-mediated oocyte maturation & 17 & 0.000252864 & 0.004989844 \\
\hline hsa00240 & Pyrimidine metabolism & 12 & 0.000297856 & 0.00551034 \\
\hline hsa05012 & Parkinson disease & 31 & 0.000505075 & 0.008794241 \\
\hline hsa05166 & Human T-cell leukemia virus 1 infection & 28 & 0.000610833 & 0.010044803 \\
\hline hsa00270 & Cysteine and methionine metabolism & 10 & 0.001213762 & 0.018909138 \\
\hline hsa04115 & p53 signaling pathway & 12 & 0.002598093 & 0.038451783 \\
\hline
\end{tabular}


A

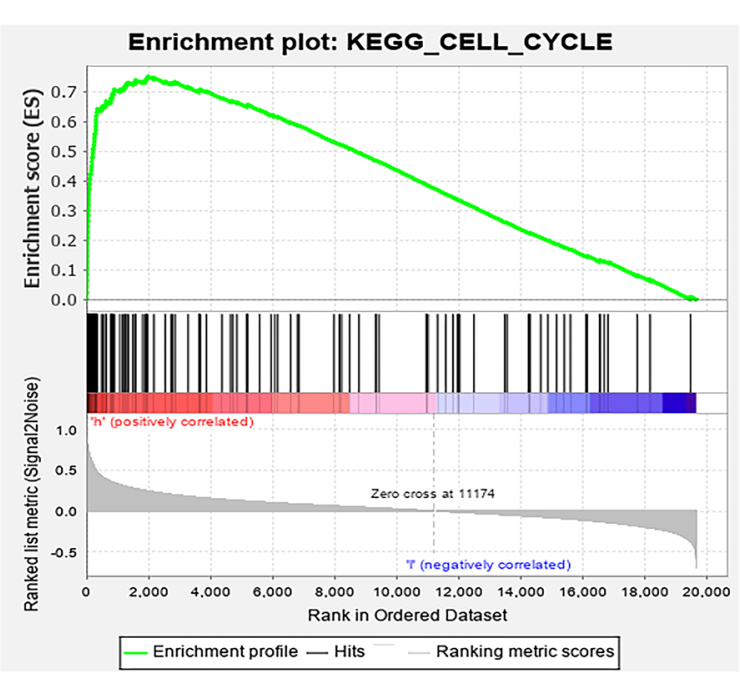

C

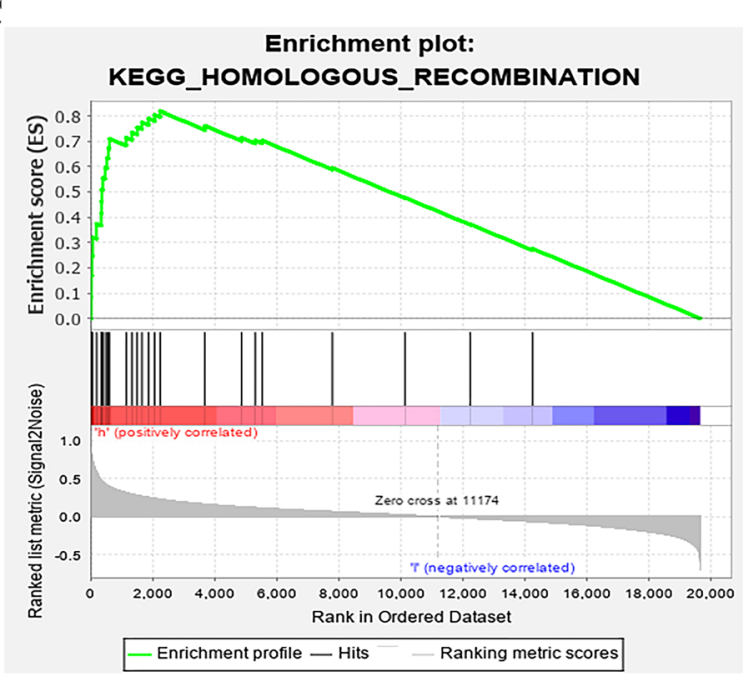

E

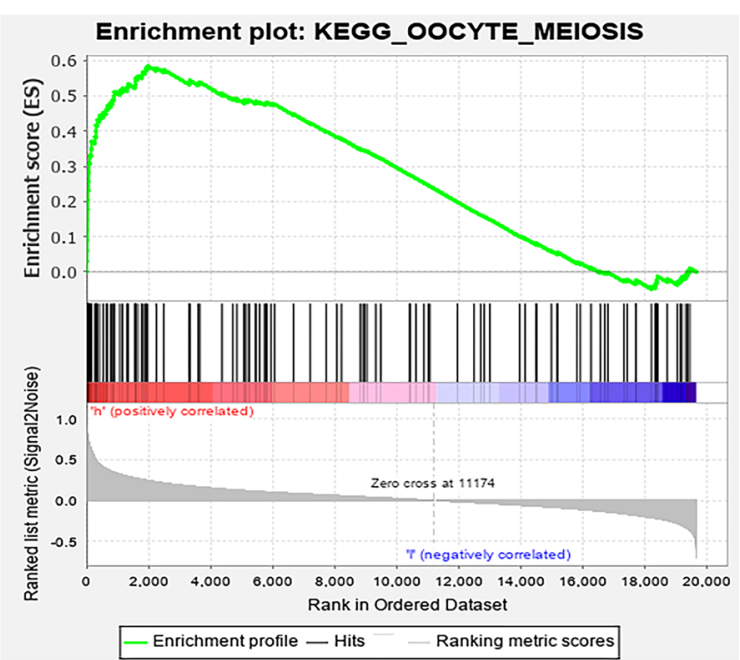

B

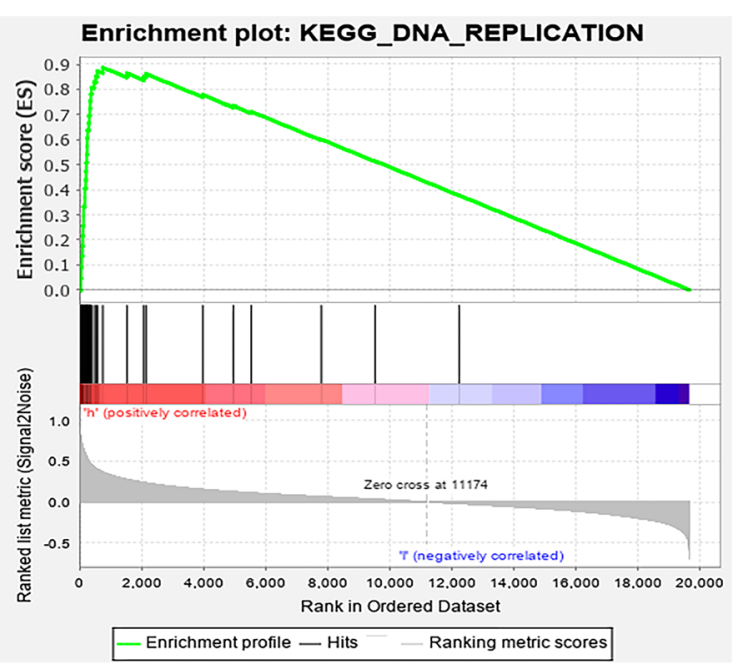

D
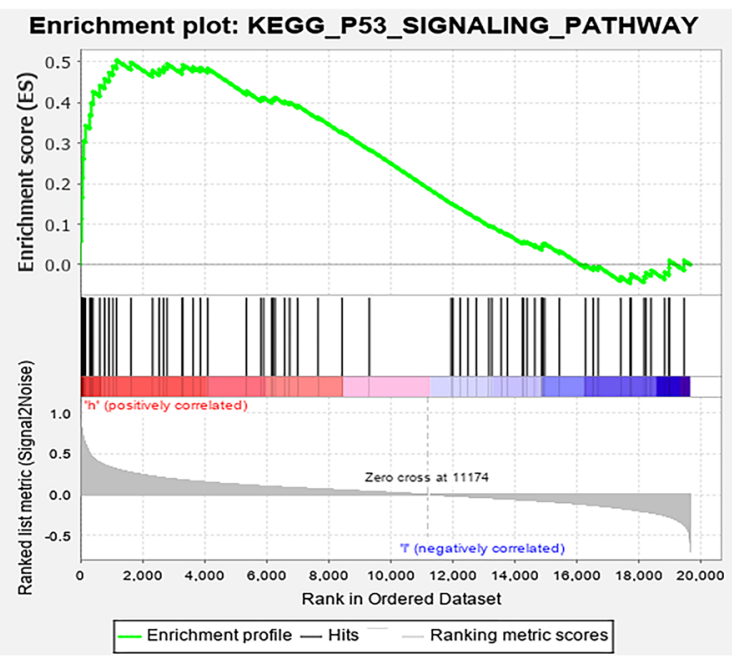

F

Enrichment plot:

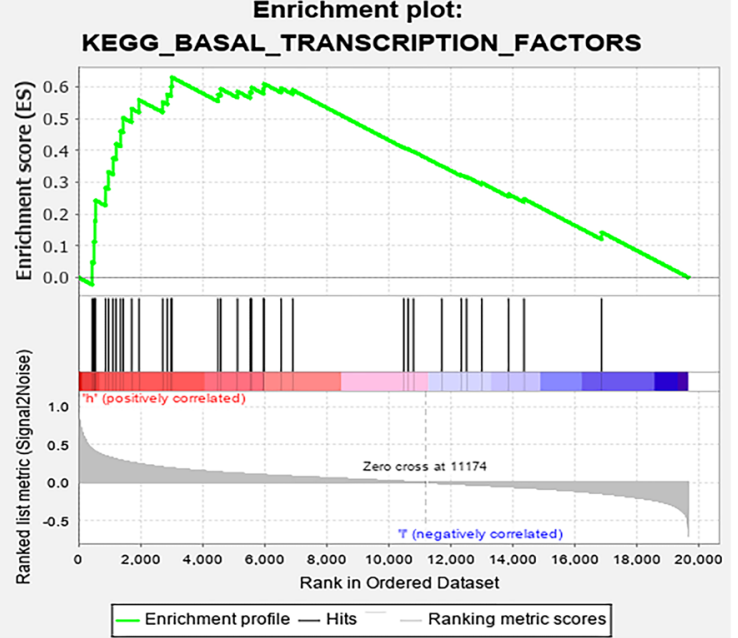

Fig. 5 GSEA displayed the main signal pathways derived from high expression of MTFR2 enrichment. A Cell cycle; B DNA replication; C Homologous recombination; D p53 signaling pathway; E Oocyte meiosis; F Base_excision_ repair 
Table 5 GSEA displayed the main signal pathways derived from high expression of MTFR2 enrichment

\begin{tabular}{|c|c|c|c|}
\hline Name & Size & Nes & Nom $p$ value \\
\hline KEGG_CELL_CYCLE & 124 & 2.5325148 & 0 \\
\hline KEGG_SPLICEOSOME & 126 & 2.342574 & 0 \\
\hline KEGG_OOCYTE_MEIOSIS & 112 & 2.3013418 & 0 \\
\hline KEGG_MISMATCH_REPAIR & 23 & 2.2582684 & 0 \\
\hline KEGG_DNA_REPLICATION & 36 & 2.210251 & 0 \\
\hline KEGG_HOMOLOGOUS_RECOMBINATION & 28 & 2.207216 & 0 \\
\hline KEGG_RNA_DEGRADATION & 57 & 2.2033587 & 0 \\
\hline KEGG_PROGESTERONE_MEDIATED_OOCYTE_MATURATION & 85 & 2.1570013 & 0 \\
\hline KEGG_PROTEASOME & 44 & 2.108183 & 0 \\
\hline KEGG_BASE_EXCISION_REPAIR & 33 & 2.097559 & 0 \\
\hline KEGG_PATHOGENIC_ESCHERICHIA_COLI_INFECTION & 55 & 2.096588 & 0 \\
\hline KEGG_GLYOXYLATE_AND_DICARBOXYLATE_METABOLISM & 16 & 2.0935147 & 0 \\
\hline KEGG_BASAL_TRANSCRIPTION_FACTORS & 35 & 2.051244 & 0 \\
\hline KEGG_PYRIMIDINE_METABOLISM & 98 & 2.0281448 & 0 \\
\hline KEGG_ONE_CARBON_POOL_BY_FOLATE & 17 & 2.0059762 & 0 \\
\hline KEGG_P53_SIGNALING_PATHWAY & 68 & 1.96642 & 0 \\
\hline KEGG_PURINE_METABOLISM & 157 & 1.9532791 & 0 \\
\hline KEGG_NUCLEOTIDE_EXCISION_REPAIR & 44 & 2.0500638 & 0.001831502 \\
\hline KEGG_UBIQUITIN_MEDIATED_PROTEOLYSIS & 133 & 1.7833992 & 0.003868472 \\
\hline KEGG_CYSTEINE_AND_METHIONINE_METABOLISM & 34 & 1.8469852 & 0.003883495 \\
\hline KEGG_FRUCTOSE_AND_MANNOSE_METABOLISM & 33 & 1.821762 & 0.011516315 \\
\hline KEGG_PENTOSE_PHOSPHATE_PATHWAY & 27 & 1.7594053 & 0.011650485 \\
\hline KEGG_N_GLYCAN_BIOSYNTHESIS & 46 & 1.6938915 & 0.023346303 \\
\hline KEGG_BLADDER_CANCER & 42 & 1.5152026 & 0.0251938 \\
\hline KEGG_RIBOFLAVIN_METABOLISM & 16 & 1.5648233 & 0.027675277 \\
\hline KEGG_PANCREATIC_CANCER & 70 & 1.4912151 & 0.03131524 \\
\hline KEGG_GLYCOLYSIS_GLUCONEOGENESIS & 62 & 1.5601822 & 0.036398467 \\
\hline KEGG_HUNTINGTONS_DISEASE & 177 & 1.6180334 & 0.046511628 \\
\hline KEGG_RNA_POLYMERASE & 29 & 1.5426548 & 0.048732944 \\
\hline
\end{tabular}

pathways by KEGG. Secondly, in GSEA, we also found that cell cycle, DNA replication, homologous recombin-

Table 6 The top 10 Hub genes in PPI Network

\begin{tabular}{lll}
\hline Name & Description & Score \\
\hline CDK1 & Cyclin dependent kinase 1 & 192 \\
CDC20 & Cell division cycle 20 & 160 \\
CCNB1 & Cyclin B1 & 138 \\
PLK1 & Polo like kinase 1 & 134 \\
CCNA2 & Cyclin A2 & 129 \\
AURKB & Aurora kinase B & 127 \\
CCNB2 & Cyclin B2 & 124 \\
BUB1B & BUB1 mitotic checkpoint serine/threonine kinase B & 118 \\
MAD2L1 & Mitotic arrest deficient 2 like 1 & 117 \\
BUB1 & BUB1 mitotic checkpoint serine/threonine kinase & 105 \\
\hline
\end{tabular}

ation and p53 signaling pathways were highly enriched in MTFR2 highly-expressed group. Up to now, it was found that interfering with MTFR2 affected the process of EMT [8], but the role of MTFR2 in LUAD was still not been elucidated. However, MTFR2 promoted mitochondrial division in cells, which was related to tumor progression. Therefore, the interaction between MTFR2 with cell cycle, DNA replication, homologous recombination and p53 signaling pathway was worth in-depth study in LUAD.

Differential expression of genes in the process of tumorigenesis and development regulated the progression of cancers and affected the prognosis [20-23]. Pololike kinase1 (PLK1) was a key regulatory factor in cell cycle and apoptosis. PLK1 was overexpressed in many 


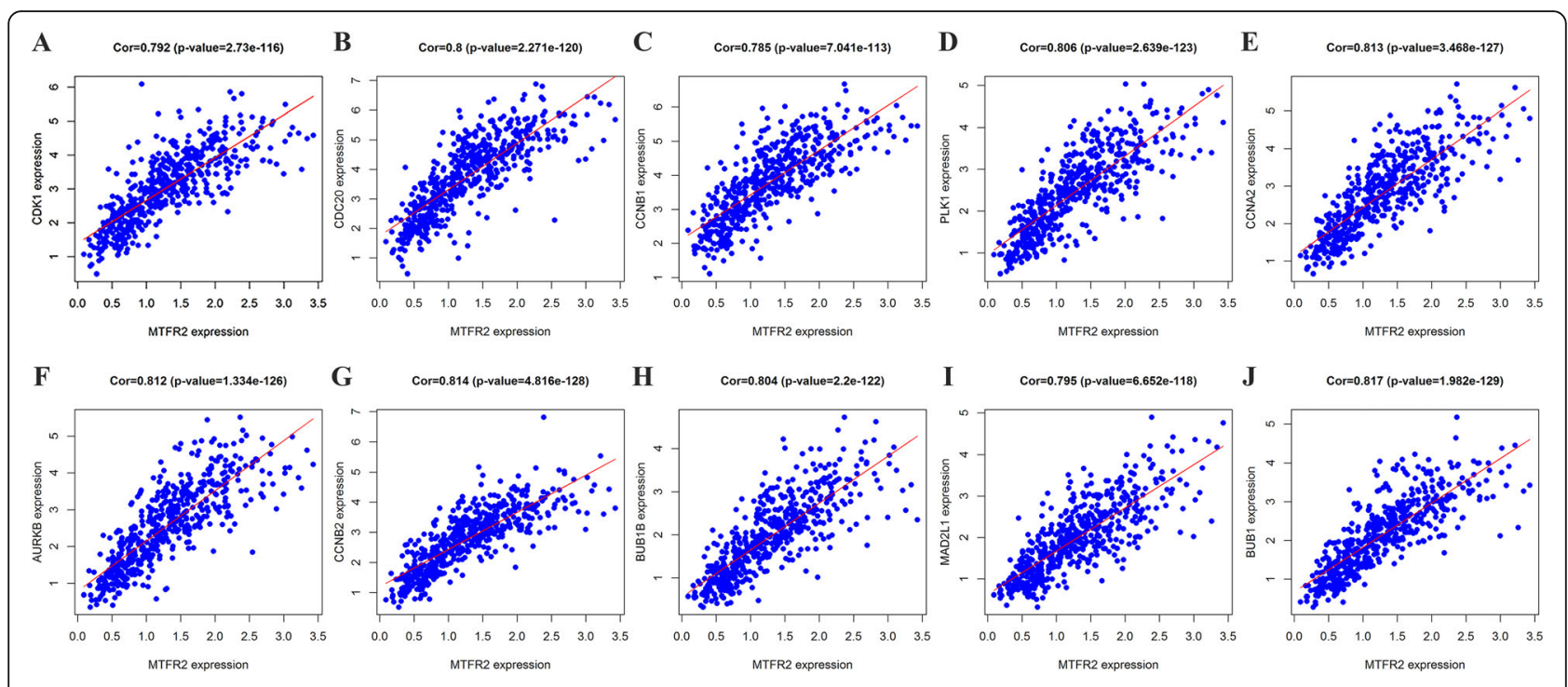

Fig. 6 The expression of MTFR2 was correlated to the top 10 Hub genes. A CDK1; B CDC20; C CCNB1; D PLK1; E CCNA2; F AURKB; G CCNB2; H BUB1B; I MAD2L 1; J BUB1

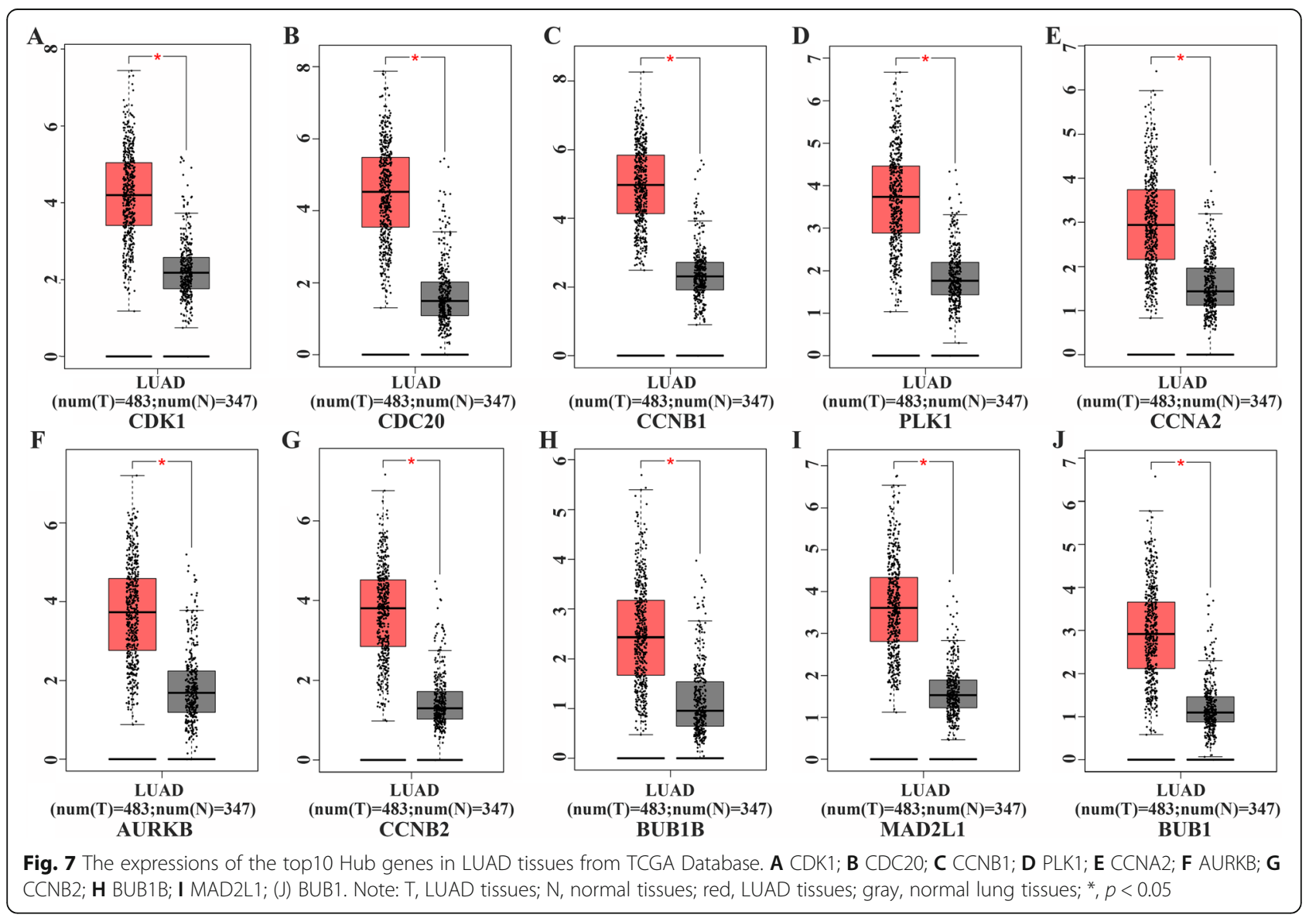



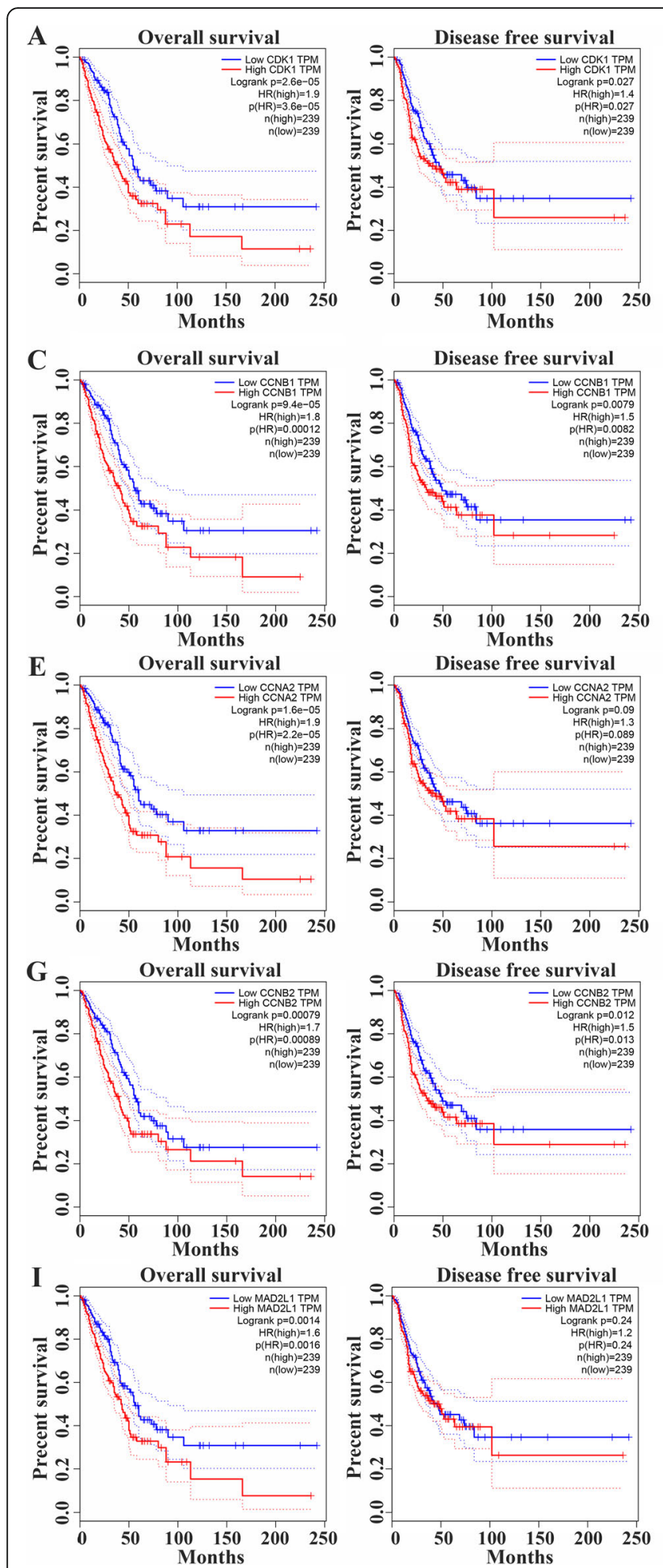
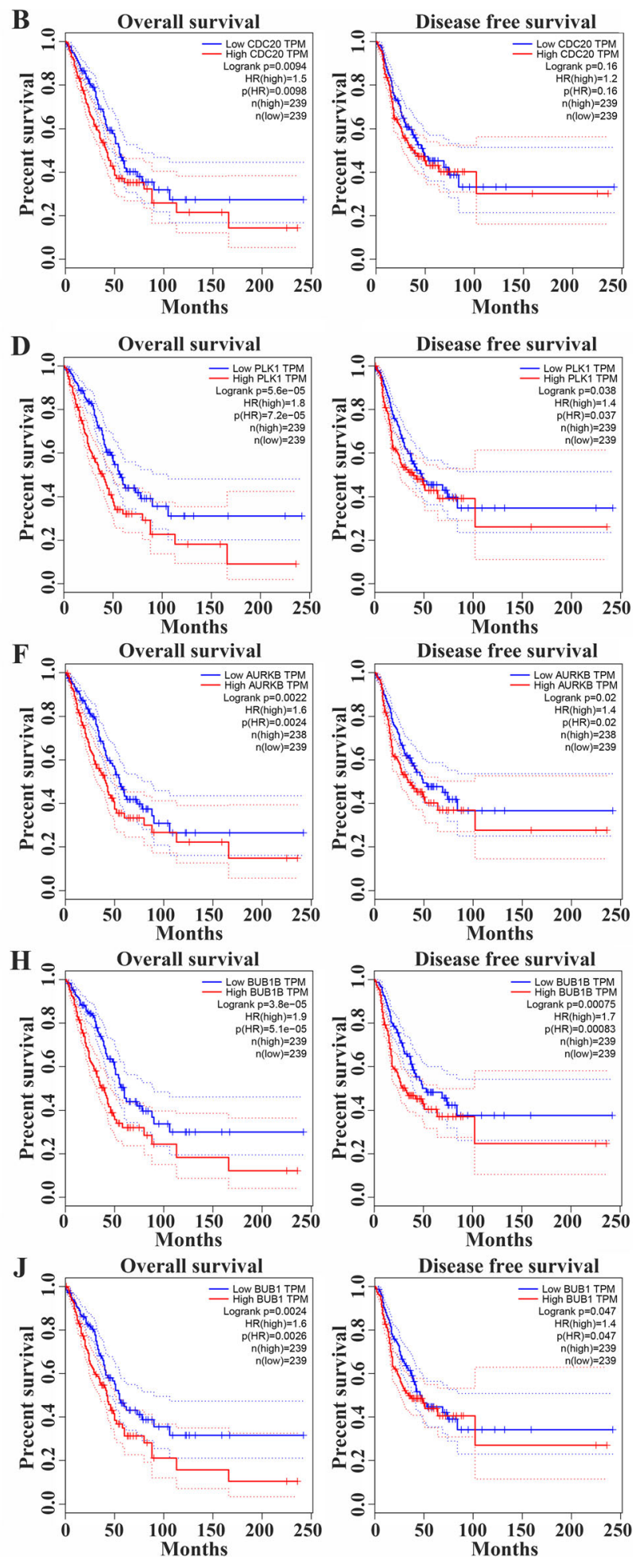

Fig. 8 The prognosis values of Hub genes in LUAD from GEPIA. A CDK1; B CDC20; C CCNB1; D PLK1; E CCNA2; F AURKB; G CCNB2; H BUB1B; I MAD2L1; J BUB1 
kinds of Cutaneous T-cell lymphomas (CTCL) cells. Down-regulation of PLK1 inhibited cell growth, stability and proliferation, and also leaded to cell cycle arrest, mitotic protein changes, apoptosis and mitotic abnormalities [20]. CCNA2 was highly expressed, and was correlated to poor prognosis in NSCLC patients [22]. Topoisomerase IIA (TOP2A) was highly expressed, and was associated with poor prognosis in LUAD, indicating that TOP2A was a prognostic marker. Knockdown of TOP2A in A549 and GLC82 cells inhibited cell proliferation, migration and invasion, and decreased the expression of CCNB1 and CCNB2, indicating that it promoted the progress of LUAD by targeting CCNB1 and CCNB2 [23]. In this study, we found that the hub genes were involved in a variety of signal pathways including those in the occurrence and development of tumors. PPI network analyzed by GEPIA showed that the expressions of CDK1, CDC20, CCNB1, PLK1, CCNA2, AURKB, CCNB2, BUB1B, MAD2L1 and BUB1 were increased and related to the overall survival (OS), and CDK1, CCNB1, PLK1, AURKB, CCNB2, BUB1B and BUB1 were associated with disease-free survival (DFS) in LUAD patients. The expression of MTFR2 was also closely related to that of CDK1, CDC20, CCNB1, PLK1, CCNA2, AURKB, CCNB2, BUB1B, MAD2L1 and BUB1, which further indicated that MTFR2 and Hub genes played an vital role in the diagnosis, treatment and disease progression of LUAD.

Generally speaking, we found that the high level of MTFR2 was related to the clinicopathological features, diagnosis and prognosis, which might be used as a potential target for diagnosis and prognosis, and MTFR2 promoted the occurrence and development through cell cycle, DNA replication, homologous recombination and p53 signal pathway in LUAD.

\section{Materials and methods Oncomine and Timer database}

The level of MTFR2 in pan-cancer tissues was analyzed by Oncomine database (https:// www.oncomine.org/ resource/login) [24] and Timer database (https:// cistrome.shinyapps.io/timer/) [25]. Screening criteria for Oncomine database: (1) Gene: FAM54A; (2) Analysis Type: Cancer vs Normal; (3) Date Type: mRNA; (4) $P<$ 0.05; (5) Fold Chang 21.5 . Search for FAM54A in the gene module of Timer database to analyze its level in pan-cancer tissues.

\section{Ualcan database}

Ualcan database (http://ualcan.path.uab.edu) [26] was used to explore the expression of MTFR2, and the correlation between the level of MTFR2 with the clinicopathological parameters (including sex, age, race, smoking history, stage, histological subtype, etc.) in LUAD.

\section{TCGA and Kaplan-Meier plotter database}

The gene expression data of 594 cases of LUAD with HTSeq-FPKM were downloaded from TCGA (https:// portal.gdc.cancer.gov/projects/) [27], including 59 cases of normal lung tissues and 535 cases of LUAD tissues. Among them, the gene expression data of 57 normal lung tissues and 57 LUAD tissues came from the same patients. TCGA data were used to analyze the expression of MTFR2 and its diagnostic value via the ROC analysis.

The clinical data of 522 patients with LUAD were downloaded and screened. The patients with unknown or incomplete clinical characteristic information and lack of prognostic follow-up data were excluded, and the rest were retained for the survival analysis, univariate Cox analysis and multivariate Cox analysis. The mRNA data for Kaplan-Meier Plotter (http://kmplot.com/analysis/) analysis [28] were derived from TCGA and GEO databases. According to the median value of MTFR2 mRNA level, the data were divided into two groups: high and low expression groups to explore the correlation with prognosis.

\section{Screening of MTFR2 co-expressed genes}

Pearson coefficient ( $r$ ) was applied to indicate the correlation between genes and reflect the biological relationship between the two genes. MTFR2 co-expressed genes were screened in 535 cases of LUAD tissues from TCGA via the $\mathrm{R}$ (version 3.6.1) [29]. Screening criteria: $P<$ 0.001 and Pearson coefficient $(r>0.4$ or $r<-0.4)$, were defined as moderate or above.

\section{GO, KEGG and GSEA}

The co-expressed genes of MTFR2 were analyzed by GO and KEGG [30] using R clusterProfiler package to explore biological function and relevant signal pathways in LUAD [27]. The gene expression data of 535 patients with LUAD from TCGA were divided into high and low expression groups according to the median MTFR2 level. The genes were arranged according to the degree of differential expression by GSEA (version 4.0.1) to explore the effect of MTFR2 on each gene. Each analysis was repeated 1000 times $[29,31]$. Screening criteria: NOM $p<0.05$.

\section{PPI network construction}

STRING (https://string-db.org/) [32] database was used to analyze the protein-protein interaction (PPI) network. Screening condition: combined score $>0.9$ was considered to be statistically significant. The obtained PPI network was introduced into Cytoscape 3.6.1 software, and the top 10 genes with high connectivity were screened by CytoHubba plug-in, and were defined as Hub genes [33]. 


\section{GEPIA database}

The mRNA data from TCGA and GTEx, and data of normal lung tissues from GEPIA database were selected to verify the expression of Hub genes in LUAD compared with normal lung tissues. According to the median value of Hub gene expressions, the data were divided into two groups: high and low expression groups, and the relationships between their levels and OS and DFS were analyzed.

\section{Abbreviations}

BP: Biological processes; CC: Cellular component; MF: Molecular function; OS: Overall survival; DFS: Disease-free survival; GEPIA: Gene Expression Profiling Interactive Analysis; MTFR2: Mitochondrial fission regulator 2; LUAD: Lung adenocarcinoma; NSCLC: Non-small cell lung cancer; EMT: Epithelial-stromal transformation; GSC: Glioma stem-like cells; RPA1: Replication protein A1; HR: Homologous recombination; RFS: Relapsefree survival; PLK1: Polo-likekinase1; CTCL: Cutaneous T-cell lymphomas; CDK: Cyclin-dependent kinase

\section{Supplementary Information}

The online version contains supplementary material available at https://doi. org/10.1186/s12885-021-08378-3.

Additional file 1: Table S1. Co-expressed gene of MTFR2.

Additional file 2: Table S2. GO analysis of MTFR2 co-expressed genes.

Additional file 3: Figure S1. PPI network displayed the relationship among MTFR2 coexpressed genes.

\section{Acknowledgments}

Thanks to Doctor Qing Luo for his nice help in the application of Databases.

\section{Authors' contributions}

This research was finished by all the authors. SYX conceived the research topic, made the research plan and directed the implementation of the whole research. KXX drafted the manuscript and processed the data. CC, XG, CQY and TY assisted to collect and analyze the data and drafted the manuscript. QWD, HX and ZJB were mainly involved in the management of data collection. All authors approved the final manuscript.

\section{Funding}

This work was supported by Grants from the National Natural Science Foundation of China (No. 81960532).

\section{Availability of data and materials}

Publicly available datasets were analyzed in this study. The datasets generated for this study could be found in TCGA (https://portal.gdc.cancer. gov/projects/TCGA-LUAD (HTSeq-FPKM)).

\section{Declarations}

Ethics approval and consent to participate Not applicable.

\section{Consent for publication}

Not applicable.

\section{Competing interests}

The authors declare no conflicts of interests.
Received: 20 December 2020 Accepted: 17 May 2021

Published online: 26 May 2021

\section{References}

1. Song Y, Chen D, Zhang X, Luo Y, Li S. Integrating genetic mutations and expression profiles for survival prediction of lung adenocarcinoma. Thoracic Cancer. 2019;10(5):1220-8. https://doi.org/10.1111/1759-7714.13072.

2. Chen QY, Zhong Q, Zhou JF, Qiu XT, Dang XY, Cai LS, et al. Conditional survival and recurrence of remnant gastric cancer after surgical resection: a multi-institutional study. Cancer Sci. 2020;111(2):502-12. https://doi.org/1 $0.1111 /$ cas. 14231

3. Mizutani K, Guo X, Shioya A, Zhang J, Zheng J, Kurose N, et al. The impact of PRDX4 and the EGFR mutation status on cellular proliferation in lung adenocarcinoma. Int J Med Sci. 2019;16(9):1199-206. https://doi.org/10.71 50/ijms.36071.

4. Okita R, Maeda A, Shimizu K, Nojima Y, Saisho S, Nakata M. PD-L1 overexpression is partially regulated by EGFR/HER2 signaling and associated with poor prognosis in patients with non-small-cell lung cancer. Cancer Immunol Immunother. 2017;66(7):865-76. https://doi.org/10.1007/s00262-01 7-1986-y.

5. Khunger M, Jain P, Rakshit S, Pasupuleti V, Hernandez AV, Stevenson J, et al. Safety and efficacy of PD-1/PD-L1 inhibitors in treatment-naive and chemotherapy-refractory patients with non-small-cell lung Cancer: a systematic review and meta-analysis. Clin Lung Cancer. 2018;19(3):e335-48. https://doi.org/10.1016/j.cllc.2018.01.002.

6. Jan YH, Lai TC, Yang CJ, Huang MS, Hsiao M. A co-expressed gene status of adenylate kinase $1 / 4$ reveals prognostic gene signature associated with prognosis and sensitivity to EGFR targeted therapy in lung adenocarcinoma. Sci Rep. 2019;9(1):12329. https://doi.org/10.1038/s41598-019-48243-9.

7. Feng J, Ma Y, Chen Z, Hu J, Yang Q, Ding G. Mitochondrial pyruvate carrier 2 mediates mitochondrial dysfunction and apoptosis in high glucosetreated podocytes. Life Sci. 2019;237:116941. https://doi.org/10.1016/j.lfs.201 9.116941.

8. Lu G, Lai Y, Wang T, Lin W, Lu J, Ma Y, et al. Mitochondrial fission regulator 2 (MTFR2) promotes growth, migration, invasion and tumour progression in breast cancer cells. Aging. 2019;11(22):10203-19. https://doi.org/10.18632/a ging.102442.

9. Wu Y, Chen M, Jiang J. Mitochondrial dysfunction in neurodegenerative diseases and drug targets via apoptotic signaling. Mitochondrion. 2019;49: 35-45. https://doi.org/10.1016/j.mito.2019.07.003.

10. Zhou Q, Li H, Li Y, Tan M, Fan S, Cao C, et al. Inhibiting neddylation modification alters mitochondrial morphology and reprograms energy metabolism in cancer cells. JCI Insight. 2019;4(4):e121582.

11. Zeng Y, Guo Z, Hu Z, Liu M, Chen Y, Chen S, et al. FGD1 exhibits oncogenic properties in hepatocellular carcinoma through regulating cell morphology, autophagy and mitochondrial function. Biomed Pharmacother. 2020;125: 110029.

12. Wang J, Xie Y, Bai X, Wang N, Yu H, Deng Z, et al. Targeting dual specificity protein kinase TTK attenuates tumorigenesis of glioblastoma. Oncotarget. 2018;9(3):3081-8. https://doi.org/10.18632/oncotarget.23152.

13. Yang M, Wang B, Gao J, Zhang Y, Xu W, Tao L. Spinosad induces programmed cell death involves mitochondrial dysfunction and cytochrome C release in Spodoptera frugiperda Sf9 cells. Chemosphere. 2017;169:155-61. https://doi.org/10.1016/j.chemosphere.2016.11.065.

14. Yang S, Liu Y, Guo Y, Liu R, Qi F, Li X, et al. Circadian gene clock participates in mitochondrial apoptosis pathways by regulating mitochondrial membrane potential, mitochondria out membrane permeablization and apoptosis factors in AML12 hepatocytes. Mol Cell Biochem. 2020;467(1-2): 65-75. https://doi.org/10.1007/s11010-020-03701-1.

15. Pan B, Zhong W, Deng Z, Lai C, Chu J, Jiao G, et al. Inhibition of prostate cancer growth by solanine requires the suppression of cell cycle proteins and the activation of ROS/P38 signaling pathway. Cancer Medicine. 2016; 5(11):3214-22. https://doi.org/10.1002/cam4.916.

16. Yue M, Li S, Yan G, Li C, Kang Z. Paeoniflorin inhibits cell growth and induces cell cycle arrest through inhibition of FoxM1 in colorectal cancer cells. Cell cycle (Georgetown, Tex). 2018;17(2):240-9.

17. Li W, Zheng G, Xia J, Yang G, Sun J, Wang X, et al. Cell cycle-related and expression-elevated protein in tumor overexpression is associated with proliferation behaviors and poor prognosis in non-small-cell lung cancer. Cancer Sci. 2018;109(4):1012-23. https://doi.org/10.1111/cas.13524. 
18. Nichols BA, Oswald NW, McMillan EA, McGlynn K, Yan J, Kim MS, et al. HORMAD1 is a negative prognostic Indicator in lung adenocarcinoma and specifies resistance to oxidative and genotoxic stress. Cancer Res. 2018; 78(21):6196-208. https://doi.org/10.1158/0008-5472.CAN-18-1377.

19. Sun H, Liu K, Huang J, Sun Q, Shao C, Luo J, et al. FAM111B, a direct target of p53, promotes the malignant process of lung adenocarcinoma. OncoTargets Ther. 2019;12:2829-42. https://doi.org/10.2147/OTT.S190934.

20. Nihal M, Stutz N, Schmit T, Ahmad N, Wood GS. Polo-like kinase 1 (PIk1) is expressed by cutaneous T-cell lymphomas (CTCLs), and its downregulation promotes cell cycle arrest and apoptosis. Cell Cycle (Georgetown, Tex). 2011;10(8):1303-11.

21. Raghavan P, Tumati V, Yu L, Chan N, Tomimatsu N, Burma S, et al. AZD5438, an inhibitor of Cdk1, 2, and 9, enhances the radiosensitivity of non-small cell lung carcinoma cells. Int J Radiat Oncol Biol Phys. 2012;84(4):e507-14. https://doi.org/10.1016/j.jijrobp.2012.05.035.

22. Ko E, Kim Y, Cho EY, Han J, Shim YM, Park J, et al. Synergistic effect of BCl-2 and cyclin A2 on adverse recurrence-free survival in stage I non-small cell lung cancer. Ann Surg Oncol. 2013;20(3):1005-12. https://doi.org/10.1245/s1 0434-012-2727-2.

23. Kou F, Sun H, Wu L, Li B, Zhang B, Wang X, et al. TOP2A promotes lung adenocarcinoma Cells' malignant progression and predicts poor prognosis in lung adenocarcinoma. J Cancer. 2020;11(9):2496-508. https://doi.org/10. 7150/jca.41415.

24. Rhodes DR, Kalyana-Sundaram S, Mahavisno V, Varambally R, Yu J, Briggs BB, et al. Oncomine 3.0: genes, pathways, and networks in a collection of 18,000 cancer gene expression profiles. Neoplasia. 2007;9(2):166-80. https:// doi.org/10.1593/neo.07112

25. Li T, Fan J, Wang B, Traugh N, Chen Q, Liu JS, et al. TIMER: a web server for comprehensive analysis of tumor-infiltrating immune cells. Cancer Res. 2017; 77(21):e108-10. https://doi.org/10.1158/0008-5472.CAN-17-0307.

26. Chandrashekar DS, Bashel B, Balasubramanya SAH, Creighton CJ, PonceRodriguez I, Chakravarthi BVSK, et al. UALCAN: a portal for facilitating tumor subgroup gene expression and survival analyses. Neoplasia. 2017;19(8):64958. https://doi.org/10.1016/j.neo.2017.05.002.

27. Guo Q, Ke XX, Liu Z, Gao WL, Fang SX, Chen C, et al. Evaluation of the prognostic value of STEAP1 in lung adenocarcinoma and insights into its potential molecular pathways via Bioinformatic analysis. Front Genet. 2020; 11:242. https://doi.org/10.3389/fgene.2020.00242.

28. Győrffy B, Surowiak P, Budczies J, Lánczky A. Online survival analysis software to assess the prognostic value of biomarkers using transcriptomic data in non-small-cell lung cancer. PLoS One. 2013;8(12):e82241. https://doi. org/10.1371/journal.pone.0082241.

29. Li X, Sun L, Wang $X$, Wang $N$, Xu K, Jiang $X$, et al. A five immune-related IncRNA signature as a prognostic target for glioblastoma. Front Mol Biosci. 2021;8:632837. https://doi.org/10.3389/fmolb.2021.632837.

30. Kanehisa M, Goto S. KEGG: Kyoto encyclopedia of genes and genomes. Nucleic Acids Res. 2000;28(1):27-30. https://doi.org/10.1093/nar/28.1.27.

31. Wu H, Zhang J. Decreased expression of TFAP2B in endometrial cancer predicts poor prognosis: a study based on TCGA data. Gynecol Oncol. 2018; 149(3):592-7. https://doi.org/10.1016/j.ygyno.2018.03.057.

32. Szklarczyk D, Gable AL, Nastou KC, Lyon D, Kirsch R, Pyysalo S, et al. The STRING database in 2021: customizable protein-protein networks, and functional characterization of user-uploaded gene/measurement sets. Nucleic Acids Res. 2021;49(D1):D605-12. https://doi.org/10.1093/nar/gkaa1 074.

33. Ma H, He Z, Chen J, Zhang X, Song P. Identifying of biomarkers associated with gastric cancer based on 11 topological analysis methods of CytoHubba. Sci Rep. 2021;11(1):1331. https://doi.org/10.1038/s41598-02079235-9.

\section{Publisher's Note}

Springer Nature remains neutral with regard to jurisdictional claims in published maps and institutional affiliations.

Ready to submit your research? Choose BMC and benefit from:

- fast, convenient online submission

- thorough peer review by experienced researchers in your field

- rapid publication on acceptance

- support for research data, including large and complex data types

- gold Open Access which fosters wider collaboration and increased citations

- maximum visibility for your research: over $100 \mathrm{M}$ website views per year

At BMC, research is always in progress.

Learn more biomedcentral.com/submissions 